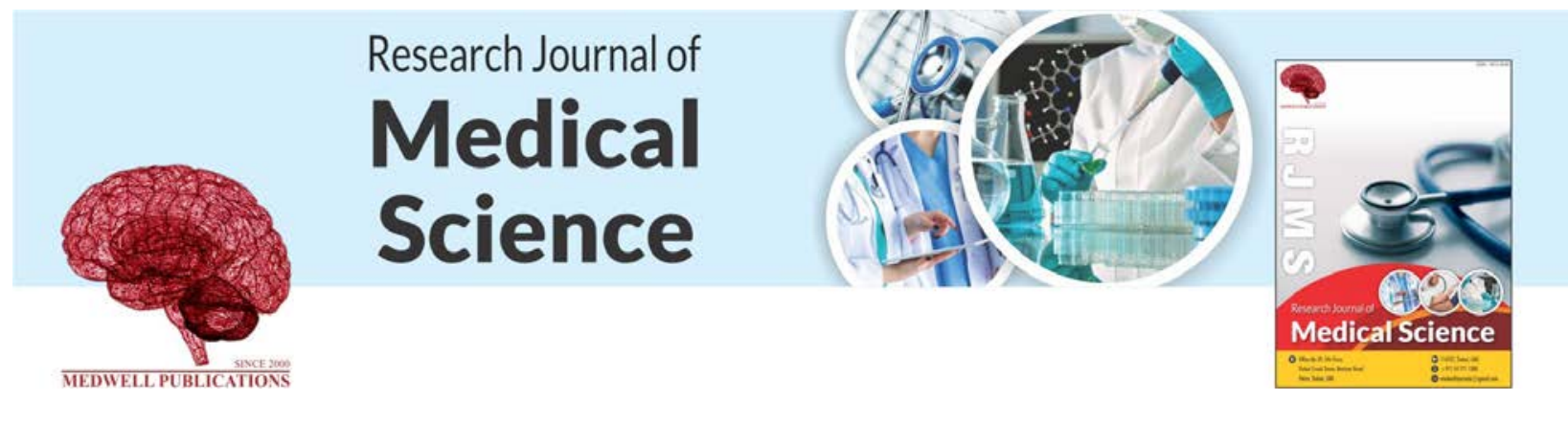

\title{
Parents Perceptions for the Causes of Intellectual Disability in their Children in Jordan
}

\author{
${ }^{1}$ Muna Mohammad Aqilan, ${ }^{2}$ Munasubhi Al Hadidi and ${ }^{3}$ Ahed J. Alkhatib \\ ${ }^{1}$ Ministry of Education \\ ${ }^{2}$ University of Jordan \\ ${ }^{3}$ Department of Legal Medicine, Toxicology of Forensic Science and Toxicology, School of Medicine, Jordan \\ University of Science and Technology, Irbid, Jordan
}

Key words: Perceptions for the causes of intellectual disability, intellectual disability, analytical approach, frequency, perceptions, adopted

\section{Corresponding Author: \\ Ahed J Alkhatib \\ Department of Medicine and Critical Care, International Mariinskaya Academy}

Page No.: 44-53

Volume: 14, Issue 3, 2020

ISSN: $1815-9346$

Research Journal of Medical Sciences

Copy Right: Medwell Publications
Abstract: The purpose of the study is to determine parents perceptions for the causes of intellectual disability in their children in Jordan according to the variables: the sex of the parent and the severity of the disability, the study adopted the descriptive analytical approach as it fits the purposes of the study. The sample of the study consisted of 176 father and 165 mother who have a son or daughter diagnose with intellectual disability in Amman to achieve the aims of the study a scale for parents perceptions for the causes of intellectual disability developed to collect data, percentages and frequencies and multiple quadratic variance were calculated to answer the questions.

\section{INTRODUCTION}

The history of persons with disabilities is ancient, since, the existence of the human being as persons with disabilities have been found in all societies. As for the causes of disability, they are not well known and have been misunderstood and the question that baffles and provokes conflict among parents for a long time and still controls so far is: What are the reasons for the disability of their children?

Historical reviews emphasized the multidisciplinary efforts that were developed internationally for disability issues, their causes and prevention and the medical profession took the first lead in caring in this field in addition to the main role that neuroscience and genetics play in discussing the causes of disability and genetics have made clear contributions to understand and identify the causes of mental disability and in this context, researches have developed for interventions to treat and prevent genetic disorders that cause mental disability. These interventions have been tested with their ethical, legal and social dimensions ${ }^{[1]}$.

Mental disability is one of the difficult problems and challenges faced by parents that result in the emergence of special needs such as cognitive needs and parents need a support system that helps them to gain information about the causes of their children's disabilities that contribute to the success of preventive programs from mental disability and play the role expected of them in Parental care and upbringing and although, it is known that the causes of mental disability for children may be related to heredity, a ratio of $>50 \%$ of the causes may not be accurately determined $^{[2]}$. Many psychologists now confirm that both inheritance and environment work together integrally to produce human attributes such as intelligence, height 
and all abilities, it cannot be confirmed that parents and heredity are the only reasons that children are disabled. Some disabilities may be related to parents in terms of the quality of their lives and the environment around them in the developmental stages. Perhaps the cause of mental disability is medicinal but the responsibility for improving the developmental patterns rests with educators and therapists which confirms the necessity of their interest in studying them ${ }^{[1]}$ and identifying the causes with specialists may help diagnose disability and know the severity of the injury and then providing appropriate early intervention. Disability prevention is achievable in many cases if parents have an awareness of the causes of disability and neglect and ignorance have been reduced and those who track the history of mental disability can note that increasing knowledge of the causes, definitions and diagnostic criteria have been suggested to improve services provided to people with mental disabilities and the development of preventive to reduce the prevalence of mental disability or worsening symptoms of programs.

The importance of studying parent's perceptions of the causes of mental disability among their children lies in the fact that the perceptions reflect their perceptions and understanding about these reasons and may reflect their cognitive needs around them in addition to the feelings of guilt for the parents by their perception that they are the reason for their children's mental disability or their belief that there are irrational causes of disability such as lives or their lack of knowledge. The reason for their children's mental disability may lead to parents suffering, feeling a sense of crisis and frustration which may have effects on the relationship between parents that affect the quality of life of their families.

The study problem: The number of Jordanian individuals with a disability who are more than five years old reached (651396) individuals according to the General Population and Housing Census in 2015 in Jordan and among every nine individuals aged 5 years and over in Jordan there is an individual with a disability at a rate of 1 and $11 \%$. The percentage of individuals with mental disabilities among them (2.2\% for females and $2,02 \%$ for males) (Department of Statistics, 2015) which is a significant proportion and through the work of the researcher with the project to support health systems and follow-up efforts to care for pregnant mothers and newborns until the age of 5 , we noticed a discrepancy in the reasons parents provide for the disability of their children and felt the necessity of researching parent's perceptions of the causes of mental disability among their children in order to reach their level of knowledge of the causes and come up with recommendations to focus on preventive and counseling and parenting programs to reduce the incidence of mental disability in addition to the impact of these perceptions on the lives of parents and their families and the researcher researched the references
Scientific and it was found through a review of the literature the existence of a number of studies surveying the causes and risk factors for mental disability based on medical records and reports but recent Arab studies that examined the parent's perceptions of the reasons for mental disability have a father A few or non-existent loyalty. The study aimed to find out the parent's perceptions of the mental disability of their children by answering the following questions:

What are the causes of mental disability in children according to the perceptions of parents in Jordan? Are there statistically significant differences at $\alpha=0.05$ in the parent's perceptions of the reasons for mental disability of their children attributable to the following variables: son's gender, severity of disability?

Study importance: Theoretical significance of the study: collecting and reviewing the relevant literature and providing it to the reader to identify the parent's perceptions of their children's mental disabilities and providing a basic base of information on these perceptions that researchers and professionals may rely on in setting up parenting counseling programs on the prevention of mental disabilities.

Applied importance of the study: Providing special tools to measure parent's perceptions of the causes of mental disability among their children and to make recommendations appropriate to the parent's perceptions about the causes of mental disability in Jordan to enhance disability prevention programs and awareness and counseling programs for families on the causes of mental disability.

Literature review: In a study, Tungraza ${ }^{[3]}$ that aimed to research parent's knowledge and perceptions of the causes of disability in Tanzania on a sample of 126 parents (91) females and (35) males between the ages of 20-45 years, from four regions of Tanzania, data was collected from the parents through interviews and the results of the study found that (52\%) of the parents know the reasons for the disability of their children and the researcher classified them as causes that can be prevented which are high temperature and convulsions, dystocia, prematurity, poor mother health conditions during pregnancy, meninges and malaria. The results of the study found that there is a relationship between parent's knowledge of the causes, family income and low educational level.

As for the study of Edwardraj et al. ${ }^{[4]}$ which was conducted on focus groups consisting of 29 mothers to know their perceptions about the causes of mental disability of their children and their experience of support in India, the study showed that most mothers refer to the causes of disability her son for medical reasons such as taking medications during pregnancy, fever, illness and poor care during pregnancy, followed by psychological 
causes such as psychological trauma, then environmental causes such as poor family support and in the end genetic causes such as inbreeding.

In a study by Croot et $a l^{[5]}$ that aimed to find perceptions about the causes of mental disability in Pakistani families on a sample of 60 parents and grandparents using the interview, the results concluded that the parents, they attribute the reasons for having a child with a mental disability in their families to spiritual reasons such as considering the child a gift from God to bring happiness to the family or testing their abilities as parents or that they were chosen for unknown reasons and assuming there is a reward for them in the future or a penalty for things they did in their lives or that this a child with a disability as a result of working with demons and spirits. The other reason was the presence of biological reasons such as lack of oxygen and nervous system defects at birth that affected mental and physical development while some mothers determined their responsibility for the reason for their children's mental disability as a result of what they did before and during childbirth and talked about the number of loads, their timing and premature birth and a small percentage she considered the cause of the disability to be an infection of others with it.

In the study of Al-Jalaminah that aimed to investigate the effectiveness of an educational program in improving the level of knowledge about the causes of mental disability, on a sample of 400 parents of people with mental disabilities, a measure was used by the researcher to collect data and the results found that the level of knowledge of parents people with mental disability are low on the three dimensions of the scale (prenatal causes, during childbirth and after childbirth) and the presence of statistically significant differences on the scale of knowledge of causes attributed to sex and for the benefit of mothers and the presence of statistically significant differences on the scale due to the educational level and in favor of the educational level Bachelor. In the longitudinal study conducted by Haikura et al. ${ }^{[6]}$ that aimed to find out the causes of disability for newborns in Finland on a sample consisting of 9432 births, 119 of whom had a newborn mental disability through records and family interviews, the reasons were classified based on the results of the study and the study showed that $66.4 \%$ of cases are due to biomedical reasons for severe mental disability and that 58.8 of the causes are due to prenatal reasons, 13.4 belong to three chromosomes, $16.0 \%$ are due to brain distortions $33.6 \%$ are due to unknown reasons, $4.2 \%$ are due to post-cause causes the birth and 3.4\% return to the stage of perinatal.

Guelph performed a study on the risk of mental disability among children born with birth defects and the results showed that children born with birth defects have a susceptibility to mental disability 27 times more than the average and that most children exposed to mental disability are those with birth defects and birth defects at a rate of $26.8 \%$, children with down syndrome increased by $21.6 \%$ and who had a defect in chromosomes by $54.4 \%$. The Adkedik study which aimed to find out the parent's attitudes towards having a mentally disability child in their family in East Jerusalem within the variable of parent's knowledge of their son's disability and its reasons, found that the parent's answer was yes to know the causes of mental disability by $32.4 \%$ for genetic causes and by $21.7 \%$ for the child's disease and the causes that are due to a medical error by $26.2 \%$ and the causes of environmental neglect were by $3.4 \%$.

In the longitudinal study of McDermat et al. ${ }^{[7]}$ that aimed to study the risks of mental birth births for pregnant women during pregnancy in America by tracking maternal medical history and medical records during pregnancy, the study showed that the risk of developing brain damage and increasing the risk of mental disability was $16 \%$.

Dukin et $a l .^{[8]}$ conducted a study to find out the prenatal and postpartum risk factors for mental disability using a survey questionnaire in Bangladesh and found out The severity of mental disability was $29.24 \%$ for brain infections in the postpartum period, $15.3 \%$ for inbreeding, repeated pregnancies by 2.61 and $3.68 \%$ for premature birth and finally, maternal education decreased by $2.48 \%$.

\section{MATERIALS AND METHODS}

Study methodology: The descriptive, analytical, approach was used to suit the nature of the study and achieve its objectives.

Study population: The study population which includes all parents of children diagnosed with mental disability has been enrolled in special education centers in Amman, estimated at (3500) according to the center's records.

Study sample: The sample of the study was selected from the study population of 341 from the parents of persons with mental disabilities who are diagnosed and enrolled in special education centers and special rooms attached to schools of the Ministry of Education in Amman Governorate within the categories of simple, medium and severe mental disabilities who are over 5 years old by way of the sample available who cooperated and agreed to respond to the study tool according to the parent's gender variable, son's handicap severity and Table 1 shows the characteristics of the sample.

Table 1: Frequencies and percentages of study variables

\begin{tabular}{lcc}
\hline Parameters & Frequencies $(\mathrm{N})$ & Percentage \\
\hline Gender/variables & & \\
Male & 176 & 51.6 \\
Female & 165 & 48.4 \\
Handicap intensity & & \\
Simple & 86 & 25.2 \\
Intermediate & 179 & 52.2 \\
Severe & 76 & 22.3 \\
Total & 341 & 100 \\
\hline
\end{tabular}


Res. J. Med. Sci., 14 (3): 44-53, 2020

Table 2: Correlation coefficients between paragraphs, total score and related dimension

\begin{tabular}{|c|c|c|c|c|c|c|c|c|}
\hline Item No. & $\begin{array}{l}\text { Correlation } \\
\text { factor }\end{array}$ & $\begin{array}{l}\text { Correlation } \\
\text { factor }\end{array}$ & Item No. & $\begin{array}{l}\text { Correlation } \\
\text { factor }\end{array}$ & $\begin{array}{l}\text { Correlation } \\
\text { factor }\end{array}$ & Item No. & $\begin{array}{c}\text { Correlation } \\
\text { factor }\end{array}$ & $\begin{array}{l}\text { Correlation } \\
\text { factor }\end{array}$ \\
\hline 1 & $0.71^{* *}$ & 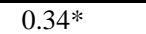 & 17 & $0.59^{*}$ & 0.448 & 33 & $0.74^{* *}$ & $0.63^{* *}$ \\
\hline 2 & $0.73 * *$ & $0.61 * *$ & 18 & $0.48 * *$ & $0.41^{*}$ & 34 & $0.64 * *$ & $0.52 * *$ \\
\hline 3 & $0.72 * *$ & $0.43 *$ & 19 & $0.72 * *$ & $0.57 * *$ & 35 & $0.83 * *$ & $0.82 * *$ \\
\hline 4 & $0.80^{* *}$ & $0.44 *$ & 20 & $0.53^{* *}$ & $0.36 *$ & 36 & $0.72 * *$ & $0.61 * *$ \\
\hline 5 & $0.66 * *$ & $0.47 * *$ & 21 & $0.80 * *$ & $0.54^{* *}$ & 37 & $0.74 * *$ & $0.63 * *$ \\
\hline 6 & $0.62 * *$ & $0.44 * *$ & 22 & $0.83 * *$ & $0.49 * *$ & 38 & $0.80 * *$ & $0.76^{* *}$ \\
\hline 7 & $0.75 * *$ & $0.62 * *$ & 23 & $0.68 * *$ & $0.58 * *$ & 39 & $0.46^{*}$ & $0.50 * *$ \\
\hline 8 & $0.46^{*}$ & $0.63 * *$ & 24 & $0.70 * *$ & $0.57 * *$ & 40 & $0.63 * *$ & $0.70 * *$ \\
\hline 9 & $0.54 * *$ & $0.38 *$ & 25 & $0.86 * *$ & $0.38 *$ & 41 & $0.42 *$ & $0.44 *$ \\
\hline 10 & $0.88 * *$ & $0.85^{* *}$ & 26 & $0.69 * *$ & $0.43 *$ & 42 & $0.80 * *$ & $0.76^{* *}$ \\
\hline 11 & $0.46^{*}$ & $0.63 * *$ & 27 & $0.45 *$ & $0.63 * *$ & 43 & $0.70 * *$ & $0.63 * *$ \\
\hline 12 & $0.63 * *$ & $0.60 * *$ & 28 & $0.55^{* *}$ & $0.41 *$ & 44 & $0.79 * *$ & $0.64 * *$ \\
\hline 13 & $0.66 * *$ & $0.76 * *$ & 29 & $0.68 * *$ & $0 . .52 * *$ & 45 & $0.54 * *$ & $0.37 *$ \\
\hline 14 & $0.72 * *$ & $0.72 * *$ & 30 & $0.80 * *$ & $0.40^{*}$ & 46 & $0.75^{* *}$ & $0.60 * *$ \\
\hline 15 & $0.43 *$ & $0.38 *$ & 31 & $0.75 * *$ & $0.73 * *$ & 47 & $0.83 * *$ & $0.85 * *$ \\
\hline 16 & $0.42 *$ & $0.40 *$ & 32 & $0.60 * *$ & $0.55^{* *}$ & 48 & & \\
\hline
\end{tabular}

\section{Study instrument}

A measure to reveal parent's perceptions of their children's mental disabilities: A questionnaire was designed to obtain the responses of the respondents about their perceptions of mental disabilities among their children by referring to scientific references such as Harris and the results of previous studies such as Tungaraza ${ }^{[3]}$ and Croot et al $^{[5]}$ study which consisted of six dimensions are: genetic causes, biological environmental causes before birth, psychosocial causes before birth, biological environmental causes at birth, biological environmental causes after birth and spiritual psychological reasons and instructions were clarified to answer paragraphs either yes or no.

Validity of the tool: The validity of the study tool was verified by several methods as follows:

The apparent honesty: The two researchers extracted the apparent honesty of the scale by reviewing the primary form of the scale to ensure the importance of the paragraphs and the degree of clarity and how to respond to them by referring to the theoretical literature and previous studies similar to the study that prepared the scale to achieve its objectives.

Authenticate the content: The sincerity of the content was confirmed by the logical judgment on the study tools by relying on the honesty of the arbitrators as the tool was presented to a number of experts in the field of pediatrics and faculty members of the special education and growth psychology from several universities to ensure that the paragraphs fit the scale and the integrity of the language formulation. The arbitrators agreed on the validity of the scale while giving some adjustments that were modified in accordance with a large number of them by $80 \%$.

Construction validity: To extract the significance of construction ratios for the scale, the parameters of the correlation of the scale paragraphs with the total score were extracted in an exploratory sample from outside the study sample consisting of 30 individuals. Its correlation with the dimension it belongs to and between each dimension and the total score on the other hand. Paragraph correlation coefficients with the instrument as a whole ranged between (0.34-0.85) and with the dimension (0.42-0.88) as shown in Table 2.

It should be noted that all correlation coefficients were of acceptable and statistically significant degrees and therefore none of these paragraphs was deleted. Also, the correlation coefficient was extracted for each dimension in the total degree and the correlation coefficients between the dimensions of each other (Table 3).

It should be noted that all correlation coefficients were of acceptable and statistically significant degrees and therefore, none of these paragraphs was deleted.

The stability of the tool: To ensure the consistency of the study tool, the test-retest method was checked by applying the scale and re-applying it after two weeks to a group outside the study sample consisting of 30 individuals. Then, Pearson correlation coefficient was calculated between their two times. The stability coefficient was also calculated by the method of internal consistency according to the Cronbach alpha equation and Table 4 shows the coefficient of internal consistency according to the Cronbach alpha equation and the return stability for the dimensions and the overall degree and these values were considered appropriate for the purposes of this study.

Study procedures: The two researchers reviewed the previous studies and previous theoretical literature on the subject of the study in order to develop the study tool. Then she determined the study population and the method of choosing the study sample from it, specifications and size according to data of special 
Res. J. Med. Sci., 14 (3): 44-53, 2020

Table 3: Correlation coefficients between dimensions and the total score

\begin{tabular}{|c|c|c|c|c|c|c|c|}
\hline Correlation & 1 & 2 & 3 & 4 & 5 & 6 & 7 \\
\hline 1 & 1 & & & & & & \\
\hline 2 & $0.475^{*}$ & 1 & & & & & \\
\hline 3 & $0.517^{* *}$ & $0.682^{* *}$ & 1 & & & & \\
\hline 4 & $0.522^{* *}$ & $0.614^{* *}$ & $0.578^{* *}$ & 1 & & & \\
\hline 5 & $0.506^{* *}$ & $0.844^{* *}$ & $0.728^{* *}$ & $0.367 *$ & 1 & & \\
\hline 6 & $0.457 *$ & $0.785^{* *}$ & $0.597 * *$ & $0.452 *$ & $0.804^{* *}$ & 1 & \\
\hline 7 & $0.674 * *$ & $0.874^{* *}$ & $0.717 * *$ & $0.517^{* *}$ & $0.936^{* *}$ & $0.846^{* *}$ & 1 \\
\hline \multicolumn{8}{|c|}{$\begin{array}{l}1=\text { Dimension of inheritance reasons; } 2 \text { = Environmental-biological reasons before delivery; } 3 \text { = Dimension of socio-psychological factors during } \\
\text { pregnancy; } 4=\text { Environmental-biological reasons during delivery; } 5=\text { Environmental-biological reasons post delivery; } 6 \text { = Dimension of spiritual } \\
\text { psychological reasons; } 7=\text { Total reasons; }{ }^{*} \alpha=0.05 ;{ }^{* *} \alpha=0.001\end{array}$} \\
\hline \multirow{2}{*}{\multicolumn{4}{|c|}{ Domains }} & tability & sions & score & \\
\hline & & & & Coefficie & & & Crobanch \\
\hline \multicolumn{4}{|c|}{ Dimension of inheritance reasons } & 0.92 & & & 0.83 \\
\hline \multicolumn{4}{|c|}{ Environmental-biological reasons before delivery } & 0.88 & & & 0.82 \\
\hline \multicolumn{4}{|c|}{ Dimension of socio-psychological factors during pregnancy } & 0.75 & & & 0.74 \\
\hline \multicolumn{4}{|c|}{ Environmental-biological reasons during delivery } & 0.82 & & & 0.77 \\
\hline \multicolumn{4}{|c|}{ Environmental-biological reasons post delivery } & 0.86 & & & 0.85 \\
\hline \multicolumn{4}{|c|}{ Dimension of spiritual psychological reason } & 0.88 & & & 0.74 \\
\hline \multicolumn{4}{|c|}{ Total reasons } & 0.78 & & & 0.93 \\
\hline
\end{tabular}

education centers and special rooms attached to the schools of the Ministry of Education in the capital city of Amman. After obtaining the approvals and special permits to facilitate the task of its work from the concerned authorities. The target sample during the period between November, 2019 and January, 2020 according to the study variables in cooperation with colleagues in special education centers and rooms attached to schools of the Ministry of Education. Then, a statistical analysis was performed to extract the results, discuss them and come up with recommendations.

\section{RESULTS AND DISCUSSION}

Statistical analysis: Descriptive and inferential statistical analysis methods were used using SPSS Software. To answer the first study question, iterations and percentages were calculated and a classification was determined for the parent's perception of his son's mental disabilities.

To answer the second study question, arithmetic averages and standard deviations of parent's perceptionsof the causes and the calculation of multiple quadratic variance and dimensional differences in a Sheffe way.

The results of the study and its discussion: Through, the use of appropriate statistical analysis methods, the results were extracted and the results that were extracted from the study were as follows: results related to the first study question which states:

What are the causes of mental disability in children according to the perceptions of parents in Jordan? To answer this question, the frequency and percentages of the causes of mental disability among the children were extracted according to the perceptions of their parents in Jordan and Table 5 shows that.

According to Table 5, spiritual psychological reason ranks first with the highest frequency (135), 39.6\%. This was followed by environmental-biological reasons during delivery with a frequency of 135, percentage (17\%). On the other hand, environmental-biological reasons post-delivery ranks the last with a frequency of $25,7.3 \%$. The frequencies and percentages for study sample were computed for study paragraphs:

Dimension of inheritance reasons: As shown in Table 6, congenital brain anomalies came first with the highest frequency of 92 and with a percentage of $27 \%$, followed by genes inherited from the father's side with a frequency of 62 and with a percentage of $18.2 \%$ while the Rhesus factor (Rh) came last with a frequency of 24 and with a percentage of $7 \%$.

Environmental-biological reasons before delivery: Table 7 shows that non-spacing pregnancies came first with the highest frequency of 111 and with a percentage of $32.6 \%$, followed by the mother's age at pregnancy with a frequency of 87 and with a percentage of $25.5 \%$ while the mother's infection with viral diseases came last with a frequency of 5 and percentage of $1.5 \%$.

Dimension of socio-psychological factors during pregnancy: Table 8 shows that the mother's injury with prenatal depression came first with the highest frequency (74) and with a percentage of $21.7 \%$, followed by family 
Res. J. Med. Sci., 14 (3): 44-53, 2020

Table 5: Frequencies and percentages of causes of mental disability among children according to the perceptions of their parents in Jordan

\begin{tabular}{lcc}
\hline Domains & Frequencies $(\mathrm{N})$ & Percentage \\
\hline Dimension of spiritual psychological reason & 135 & 39.6 \\
Environmental-biological reasons during delivery & 58 & 17.0 \\
Dimension of inheritance reasons & 50 & 14.7 \\
Dimension of socio-psychological factors during pregnancy & 40 & 11.7 \\
Environmental-biological reasons before delivery & 33 & 9.7 \\
Environmental-biological reasons post delivery & 25 & 7.3 \\
Total & 341 & 100.0 \\
\hline
\end{tabular}

Table 6: Frequencies and percentages for the dimension of inheritance reasons

\begin{tabular}{lllcr}
\hline Orders & No. & Items & Frequencies (N) & Percentage \\
\hline 1 & 5 & Congenital brain malformations & 92 & 27.0 \\
2 & 1 & Genes inherited from the father's side & 62 & 61 \\
3 & 3 & An imbalance in the number of chromosomes inherited from the father's side & 59 & 18.2 \\
4 & 4 & An imbalance in the number of chromosomes inherited from the mother's side & 56 & 17.9 \\
5 & 2 & Genes inherited from the mother's side & 28 & 16.4 \\
6 & 6 & Relative's marriage & 24 & 8.2 \\
7 & 7 & Rh/blood group variation & & 7.0 \\
\hline
\end{tabular}

Table 7: Frequencies and percentages of environmental-biological reasons before delivery

\begin{tabular}{lllrr}
\hline Order & No. & Items & Frequencies (N) & Percentage \\
\hline 1 & 20 & Non-spacing pregnancies & 111 & 32.6 \\
2 & 15 & Mother's age at pregnancy & 87 & 25.5 \\
3 & 14 & Mother's smoking at age & 70 & 23.5 \\
4 & 17 & Poor health care for the mother during pregnancy & 60 & 20.5 \\
5 & 12 & The mother's intake of medications during pregnancy & 59 & 17.6 \\
6 & 18 & Fatigue of the mother with repeated deliveries & 57 & 17.3 \\
7 & 16 & Malnutrition of mothers during pregnancy & 55 & 16.7 \\
8 & 10 & Mother's disease during pregnancy & 35 & 16.1 \\
9 & 8 & Mother's exposure to radiation during pregnancy & 35 & 10.3 \\
10 & 9 & Increased temperature of mother during pregnancy & 24 & 10.3 \\
11 & 19 & Vaccinations the mother took during pregnancy & 16 & 7.0 \\
12 & 13 & Mother's smoking during pregnancy & 5 & 14.7 \\
13 & 11 & Viral infection of mothers & & 1.5 \\
\hline
\end{tabular}

problems during pregnancy with a frequency of 69 and with a percentage of $20.2 \%$ while the condition came the psychological trauma of the mother during pregnancy at the last rank with a frequency of 32 and a percentage of $(9.4 \%)$.

Dimension of biological environmental factors during delivery: Table 9 shows that the lack of oxygen during childbirth came first with the highest frequency of 130 and with a percentage of $38.1 \%$, followed by early childbirth and childbirth difficult with frequency of 64 and with a percentage of $18.8 \%$ while birth aspiration from the head at the last rank with a frequency of 8 and with a percentage of $2.3 \%$.

Dimension of environmental biological reasons post delivery: Table 10 shows that the child's temperature rise came first with the highest frequency of 79 and a percentage of $23.2 \%$, followed by child fall accidents with a frequency of 78 and a percentage of $22.9 \%$ while housing came in industrial areas. In the last rank with a frequency of 14 and with a percentage of $4.1 \%$.

Dimension of spiritual psychological reasons: Table 11 shows that God's exams came first with the highest repetition of 290 and with a percentage of 85\%, followed by envy with an eye with a frequency of 57 and with a percentage of $16.7 \%$ while satanic touch came last with a repetition of 13 and with a percentage of 3.8\%.

By analyzing the results of the study, we see that it intersects with some of the results of previous studies on the causes of mental disability that parents perceive of their children in terms of the arrangement of dimensions such as the study by Croot et al. ${ }^{[5]}$ who explained that parents refer the causes of a child with a mental disability in their family to spiritual reasons such as considering the child a gift from God to bring happiness to the family or testing their abilities as parents or that they were chosen for unknown reasons and assuming there is a reward for them in the future or a penalty for things they did in their lives or that this child with a disability is a result of working with demons and spirits. And secondly after biological environmental causes during childbirth such as lack of oxygen, then the responsibility of the mother for the reason for her son's mental disability as a result of what she did before and during childbirth and the number and timing of pregnancy and premature birth and crossed with some studies on the causes and differed in the arrangement of dimensions such as the study by Edwardraj et al. ${ }^{[4]}$ which showed that mothers in India refer to the causes of her son's disability for medical reasons such as taking medications during pregnancy, fever, illness and poor care 
Res. J. Med. Sci., 14 (3): 44-53, 2020

Table 8: Frequencies and percentages of the dimension of socio-psychological factors during pregnancy

\begin{tabular}{lllcr}
\hline Orders & No. & Items & Frequencies (N) & Percentage \\
\hline 1 & 22 & The mother has prenatal depression & 74 & 21.7 \\
2 & 21 & Family problems during pregnancy & 69 & 20.2 \\
3 & 24 & Poor economic status & 38 & 11.1 \\
4 & 22 & Poor psychological state of the mother during pregnancy & 32 & 9.4 \\
\hline
\end{tabular}

Table 9: Frequencies and percentages of the dimension of biological environmental factors during delivery

\begin{tabular}{lllrr}
\hline Orders & No. & Items & Frequencies $(\mathrm{N})$ & Percentage \\
\hline 1 & 25 & Oxygen insufficiency during pregnancy & 130 & 34 \\
2 & 26 & Premature birth & 64 & 18.1 \\
3 & 28 & Obstructed labor & 60 & 18.8 \\
4 & 29 & Infection and contamination during childbirth & 60 & 17.6 \\
5 & 30 & Lack of care during childbirth & 8 & 17.6 \\
6 & 27 & Delivery by aspiration from the head & 2.3 \\
\hline
\end{tabular}

Table 10: Frequencies and percentages of Dimension of environmental biological reasons post delivery

\begin{tabular}{lllcc}
\hline Order & No. & Items & Frequencies (N) & Percentage \\
\hline 1 & 32 & Increased temperature of infant & 79 & 23.2 \\
2 & 40 & Infant falling accidents & 78 & 22.9 \\
3 & 39 & Cerebral injuries & 62 & 18.2 \\
4 & 34 & Vaccinations given to the infant & 51 & 15 \\
5 & 31 & New inborn infection with viral diseases such as encephalitis and pulmonary infection & 40 & 11.7 \\
6 & 41 & Infant maltreatment & 37 & 10.9 \\
7 & 35 & Vaccinations were not given for the infant timely & 35 & 10.3 \\
8 & 33 & Infant malnutrition & 33 & 9.7 \\
9 & 36 & Polluted air & 24 & 7 \\
10 & 37 & Infant's food contains industrial colors and preservatives & 20 & 5.90 \\
11 & 4 & Shaking of the infant in bed or between hands & 18 & 5.3 \\
12 & 38 & Living in industrial areas & 14 & 4.1 \\
\hline
\end{tabular}

Table 11: Frequencies and percentages of Dimension of spiritual psychological reasons

\begin{tabular}{lllrr}
\hline Orders & No. & Items & Frequencies (N) & Percentage \\
\hline 1 & 45 & Test of faith in God & 290 & 85.0 \\
2 & 46 & Eye and envy & 57 & 16.7 \\
3 & 43 & A punishment from God for a sin i committed & 48 & 14.1 \\
4 & 44 & Magic works & 25 & 7.3 \\
5 & 47 & Satanic touch & 13 & 3.8 \\
\hline
\end{tabular}

during pregnancy, followed by psychological causes such as trauma. Then, environmental causes such as poor family support and ultimately genetic causes such as inbreeding and a study Edkedik that showed that the parent's answer was yes to know the causes of mental disability by $32.4 \%$ for genetic reasons and by $21.7 \%$ for the child's illness and the causes that are due to an error medical by $26.2 \%$ and the most important causes the environmental results were $3.4 \%$. Also, the results of the study crossed the causes of mental disability with the type of reasons that studies reached through the medical records and files for people with mental disabilities in such as the ${ }^{[9]}$ study which showed that children born with birth defects are susceptible to disability. Mentality is 27 times more than normal and most children at risk of mental disability are those with birth defects and birth defects by $26.8 \%$, children with down syndrome by $21.6 \%$ and who have chromosomal abnormalities by $54.4 \%$ and the McDermott et al. ${ }^{[7]}$ study that showed that the risk of developing brain dysfunction and increasing the risk of mental disability due to maternal infections during pregnancy was $16 \%$ and a study ${ }^{[8]}$ in Bangladesh which concluded that the degree of severity of mental disability was $29.24 \%$ for brain infections in the stage postpartum, $15.3 \%$ for inbreeding, repeat pregnancy by 2.61 and $3.68 \%$ for premature birth and finally, maternal education decreased by $2.48 \%$.

The researchers attribute these results to the effect of many factors on the formation of parent's perceptions of the reasons for the mental disability of their children such as the social component as the social component affects perceptions through what is mentioned in myths, customs and traditions, repeated social attitudes and this effect results in the spread of certain perceptions on a wide range characterized by its firmness and difficulty in correcting it even if it is wrong and similar cultural factors may lead to the formation of similar perceptions, psychological and emotional factors: the psychological formation of the individual affects perceptions that he forms from the outside world and this effect varies 
according to medicine Ah attitudes and issues perceived, so, the aggregate perceptions of past experiences and emotional situations associated and experienced by the individual. Development factors as the nature of the relationship growth between the individual and the perceived subject matter determine the constructed perceptions.

Finally, the context: the diversity of contexts during which perceptions are formed or during which recalls occur leads to differing perceptions ${ }^{[10]}$ where the highest frequency of mental disability causes the distance to spiritual reasons, especially the "Test for Me from God" clause and this perception confirms that parents are driven by their faith in God Almighty they accept that their son's disability is an exam that requires them to accept God's judgment and patience which causes them to accept their son and work to provide services to this son for a fee or they persuaded themselves with this reason to get out of the circle of guilt and get rid of the motive to search for the cause in their own or related factors.

Their families on consideration this is why out of their own will not trick them to get rid of the feelings of blaming oneself, here, we bring us the Hadith "Abu YahyaSuhaib bin Sinan who said: The Messenger of Allah said: How wonderful is the believer, commanded all his good and not to one but the believer: if he suffers from an illness of thanks, then it is better for him and if he suffers from it, he will be patient because of it. Goodness is either with patience and getting paid and its reflection on the degree of satisfaction with quality and life or getting rid of negative feelings that are generated by parents due to the search for the causes of disability and a study ${ }^{[11]}$ showed that the parents of persons with mental disabilities participate in religious rituals based on their beliefs spiritual that gives them a great degree of strength and confidence in themselves enables them to accept the disability of their child and provide them with psychological support to improve mental health and enable them to provide services to their son and obtain an appropriate quality of life, it is worth noting here that the perceptions of parents in the first dimension which is spiritual reasons may indicate the reasons the teleology that Aristotle spoke of which represents the intended purpose of an event and which accompanies the cause-and-effect relationship. Perceptions may retain all or some of the characteristics of their stimuli and they may be constructive and voluntary directed or involuntary and unguided.

The researchers show that the parent's perceptions of the causes of disability that intersected with the results of the survey studies according to the medical records may give a visualization of the extent of their knowledge of them and can be used to define guidelines for preventive programs that may reduce the prevalence of mental disability as the percentage of children.

Results related to the second study question: Are there statistically significant differences at the level of significance $(0.05(\alpha=)$ in the perceptions of parents of mental disability reasons for their children attributable to the following variables: parent guardian sex, severity of disability?

To answer this question, means and standard deviations for parent's perceptions about the causes of mental disability of their children were extracted according to the variables of the guardian's gender and severity of disability and Table 12 shows that.

Table 12 shows an apparent variation in means and standard deviations of parent's perceptions about the causes of mental disability of their children due to the different categories of, father sex and severity of disability.

To demonstrate the significance of the statistical differences between the means, a multiple quadratic variance analysis was used (Table 13) that showed: There were no statistically significant differences $(\alpha=0.05)$ due to the effect of the father's sex on all reasons.

There were no statistically significant differences $(\alpha=0.05)$ due to the effect of severity of disability on all causes except for prenatal genetics and biological environment during childbirth and to show the statistically significant differences between the means and dimensional comparisons were used in a verbal way as shown in Table 14. It can be shown from Table 14 that:

There were statistically significant differences ( $\alpha=0.05$ ) between simple and severe differences and the differences came in favor of severe in the genetic causes before birth.

There were statistically significant differences $(\alpha=0.05)$ between its mean and severe and the differences came in favor of severe in environmental biological causes during childbirth.

With regard to the result, "there were no statistically significant differences $(\alpha=0.05)$ due to the effect of the father's gender on all reasons. We noted that this result is inconsistent with the results of Jalamana whose results have found a statistically significant difference on the scale of parental knowledge of the causes of mental disability due to gender for the benefit of mothers, the researcher justifies this by agreeing to the ideas of parents and mothers as the crisis and shock that occur because of the presence of a son with a mental disability of the family pushes her to search for logical solutions within a 
Res. J. Med. Sci., 14 (3): 44-53, 2020

Table 12: Means and standard deviations of parents 'perceptions about the reasons of mental disability of their children by parent's gender variables, severity of disability

\begin{tabular}{|c|c|c|c|c|c|c|c|}
\hline Variables & Parameters & $\begin{array}{c}\text { Inheritance } \\
\text { reasons }\end{array}$ & $\begin{array}{l}\text { Environmental- } \\
\text { biological reasons } \\
\text { before delivery }\end{array}$ & $\begin{array}{l}\text { Socio-psychological } \\
\text { factors during } \\
\text { pregnancy }\end{array}$ & $\begin{array}{l}\text { Environmental- } \\
\text { biological reasons } \\
\text { during delivery }\end{array}$ & $\begin{array}{l}\text { Environmental- } \\
\text { biological reasons } \\
\text { post delivery }\end{array}$ & $\begin{array}{l}\text { Spiritual } \\
\text { psychological } \\
\text { reason }\end{array}$ \\
\hline \multicolumn{8}{|c|}{ Gender of parents } \\
\hline \multirow[t]{2}{*}{ Male } & (M) & 1.12 & 1.88 & 0.58 & 1.03 & 1.41 & 1.28 \\
\hline & (SD) & 1.55 & 2.43 & 0.93 & 1.03 & 2.24 & 0.89 \\
\hline \multirow[t]{2}{*}{ Female } & (M) & 1.12 & 2.20 & 0.67 & 1.24 & 1.47 & 1.25 \\
\hline & (SD) & 1.62 & 2.74 & 0.99 & 1.47 & 2.24 & 0.88 \\
\hline \multicolumn{8}{|l|}{ Handicap } \\
\hline \multirow[t]{2}{*}{ Simple } & (M) & 0.66 & 2 & 0.70 & 1.16 & 0.93 & 1.21 \\
\hline & (SD) & 1.13 & 2.53 & 0.84 & 1.62 & 1.85 & 0.87 \\
\hline \multirow[t]{2}{*}{ Intermediate } & (M) & 1.12 & 2.05 & 0.50 & 0.89 & 1.46 & 1.22 \\
\hline & (SD) & 1.60 & 2.69 & 0.90 & 1.16 & 2.30 & 0.87 \\
\hline \multirow[t]{2}{*}{ Severe } & (M) & 1.63 & 2.04 & 0.83 & 1.67 & 1.97 & 1.45 \\
\hline & (SD) & 1.84 & 2.44 & 1.18 & 1.47 & 2.38 & 0.093 \\
\hline
\end{tabular}

Table 13: Analysis of multiple quadrant variation of parent's gender, severity of disability on causes of mental disability for children

\begin{tabular}{|c|c|c|c|c|c|}
\hline Variation source/domains & Square sums & Freedom degree & Mean of squares & $\mathrm{F}$ & Significance \\
\hline \multicolumn{6}{|l|}{ Parents gender } \\
\hline Inheritance before delivery & 0.105 & 1 & 0.105 & 0.044 & 0.835 \\
\hline Environmental biological before delivery & 5.446 & 1 & 5.446 & 0.819 & 0.366 \\
\hline Psychological social during pregnancy & 0.208 & 1 & 0.208 & 0.233 & 0.630 \\
\hline Environmental biological during delivery & 1.315 & 1 & 1.315 & 0.730 & 0.393 \\
\hline Environmental biological post delivery & 0.047 & 1 & 0.047 & 0.010 & 0.920 \\
\hline Psychological spiritual & 0.325 & 1 & 0.325 & 0.420 & 0.517 \\
\hline \multicolumn{6}{|l|}{ Mental disability severity } \\
\hline Inheritance before delivery & 42.510 & 2 & 21.255 & 8.806 & 0.000 \\
\hline Environmental biological before delivery & 2.888 & 2 & 1.444 & 0.217 & 0.805 \\
\hline Psychological social during pregnancy & 3.611 & 2 & 1.805 & 2.027 & 0.133 \\
\hline Environmental biological during delivery & 23.639 & 2 & 11.820 & $6 . .562$ & 0.002 \\
\hline Environmental biological post delivery & 17.666 & 2 & 8.833 & 1.903 & 0.151 \\
\hline Psychological spiritual & 1.179 & 2 & 0.589 & 0.762 & 0.468 \\
\hline Inheritance before delivery & 801.339 & 332 & 2.414 & & \\
\hline Environmental biological before delivery & 2208.364 & 332 & 6.652 & & \\
\hline Psychological social during pregnancy & 295.695 & 332 & 0.891 & & \\
\hline Environmental biological during delivery & 598.002 & 332 & 1.801 & & \\
\hline Environmental biological post delivery & 1541.034 & 332 & 4.642 & & \\
\hline Psychological spiritual & 256.817 & 332 & & & \\
\hline Inheritance before delivery & 854.070 & 340 & & & \\
\hline Environmental biological before delivery & 2275.578 & 340 & & & \\
\hline Psychological social during pregnancy & 315.953 & 340 & & & \\
\hline Environmental biological during delivery & 657.062 & 340 & & & \\
\hline Environmental biological post delivery & 1702.018 & 340 & & & \\
\hline Psychological spiritual & 267.179 & 340 & & & \\
\hline
\end{tabular}

Table 14: Dimensional comparisons in a Scheffe way: the severity of disability affects parent's perceptions of their children's mental disabilities

\begin{tabular}{|c|c|c|c|c|}
\hline Domains of dependent variable/independent variable intervals & $\mathrm{M}$ & Simple & Intermediate & Severe \\
\hline Inheritance before delivery & - & - & - & - \\
\hline Simple & 0.66 & - & - & - \\
\hline Intermediate & 1.12 & 0.46 & & \\
\hline Severe & 1.63 & $0.97 *$ & 0.51 & - \\
\hline Environmental biological during delivery & - & - & - & - \\
\hline Simple & 1.16 & - & - & - \\
\hline Intermediate & 0.89 & 0.27 & - & - \\
\hline Severe & 1.67 & 0.51 & $0.78^{*}$ & - \\
\hline
\end{tabular}

set of procedures to raise the level of compatibility between the spouses, especially, intellectual with the aim of raising the ability to endure stress and overcome crises and whenever it was religious values in family greater the greater compatibility in addition to the different impact of the social context and culture on parent's perceptions for reasons of disability.
With regard to the result "there were statistically significant differences ( $\alpha=0.05)$ between the simple and the severe and the differences were in favor of severe in the genetic causes before birth.

It converges with the results of the longitudinal study conducted by Heikura et al. ${ }^{[6]}$ which concluded that $58.8 \%$ of the causes are due to prenatal causes of 
which $13.4 \%$ are due to triple chromosomes, $16.0 \%$ are due to cerebral anomalies, severe mental disability category and they are all genetic causes mentioned in paragraphs. The scale used while educational literature indicates that environmental causes constitute $90 \%$ of the causes of simple mental disability and genetic causes constitute $10 \%$ of the causes of severe mental disability including chromosomal disorders, conditions associated with the disorder of the processes of representation of proteins and the disorder of fatty acids ${ }^{[12]}$.

"There are statistically significant differences $(\alpha=0.05)$ between mean and severe. The differences were in favor of severe in biological environmental causes during birth." It has been shown by Hymas that 70\% of severe mental disabilities are known to be due to known genetic causes and the reasons before, during and after childbirth and that only $24 \%$ of cases with minor disabilities have a known medical cause while the researchers did not find studies that found statistically significant differences between the causes of the medium and severe disability categories but educational literature indicated the importance of the large interactive role between genetic factors before birth. The factors different environmental categories for the Mental Disability category ${ }^{[1]}$ which may explain the significant difference between the mental disability category and the severe mental disability category in biological environmental causes.

\section{CONCLUSION}

The findings of the study showed that found that the spiritual causes came in first place with the highest frequency (135) and a percentage of 39.6\%, followed by biological environmental causes during childbirth with a frequency of 58 and a percentage of $17 \%$. The biological environmental causes after birth came in the last place with a frequency of 25 , a percentage of $7.3 \%$, a statistically significant relationship between parent's perceptions of the causes of mental disability in their children and the severity of disability for the benefit of people with severe disabilities and the absence of a statistically function relationship of perceptions with the sex of the parent.

\section{RECOMMENDATIONS}

Drawing on the results of the study and analyzing it, the following recommendations were reached: work to intensify counseling programs for parents to educate about the causes of mental disability and preparing educational leaflets about the causes of mental disability and employing them in mother and child care centers. Activating genetic counseling and awareness programs about its importance. Improving primary health care services for pregnant mothers and children up to 5 years to prevent disability. Further studies address differences in parent's perceptions of mental disability causes in their children such as family income and father's educational level.

\section{REFERENCES}

01. Kirk, S., J. Gallagher, M. Coleman and N. Anastaiow, 2011. Educating Exceptional Children. 13th Edn., Cengage Learning, Inc., Boston, Massachusetts, USA., ISBN-13: 978-1-111-35611-8, Pages: 391.

02. Hallahan, D. and J. Kauffman, 2006. Exceptional Learners: Introduction to Special Education. 10th Edn., Allyn and Bacon, Boston.

03. Tungaraza, F.D., 2012. Who Sinned? Parent's knowledge of the causes of disability in Tanzania. Int. J. Spec. Educ., 27: 216-224.

04. Edwardraj, S., K. Mumtaj, J.H. Prasad, A. Kuruvilla and K.S. Jacob, 2010. Perceptions about the intellectual disability: A qualitative study from velour, South India. J. Intellect Disabil. Res., 54: 736-748.

05. Croot, E.J., G. Grant, C.L. Cooper and N. Mathers, 2008. Perceptions of the causes of childhood disability among Pakistani families living in the UK. Health Social Care Community, 16: 606-613.

06. Heikura, U., S.L. Linna, P. Olsen, A.L. Hartikainen, A. Taanila and M.R. Jarvelin, 2005. Etiological survey on intellectual disability in the Northern Finland birth cohort 1986. Am. J. Mental Retardation, 110: 171-180.

07. McDermott, S., V. Daguise, H. Mann, L. SZWEKBKA and W. Callaghan, 2001. Perinatal risk for mortality and mental retardation associated with maternal urinary-tract infections. J. Family Pract., 50: 433-437.

08. Durkin, M.S., N.Z. Khan, L.L. Davidson, S. Huq, S. Munir, E. Rasul and S.S. Zaman, 2000. Prenatal and postnatal risk factors for mental retardation among children in Bangladesh. Am. J. Epidemiol., 152: 1024-1033.

09. Jelliffe-Pawlowski, L.L., G.M. Shaw, V. Nelson and J.A. Harris, 2003. Risk of mental retardation among children born with birth defects. Arch. Pediatr. Adolesc. Med., 157: 545-550.

10. Sigel, I.E., 2013. Development of Mental Representations: Theories and Applications. Psychology Press, USA.,.

11. Poston, D.J. and A.P. Turnbull, 2004. Role of spirituality and religion in family quality of life for families of children with disabilities. Educ. Training Dev. Disabilities, 39: 95-108.

12. Daily, D.K., H. Ardinger and G.E. Holmes, 2000. Identification and evaluation of mental retardation. Am. Fam. Physician, 61: 1059-1067. 